\title{
Effective Teaching In The Classroom: Can It Be Done?
}

John S. Croucher, (Email: john.croucher@mgsm.edu.au), Macquarie University, Australia

\begin{abstract}
This paper looks at some of the techniques that have been used to make the lecture theatre and classroom more effective and provides details of an astonishing Australian success story. There have been questions raised among academics about the usefulness of the traditional lecture approach that has been used for many years at universities and other tertiary institutions. With increasing calls from some quarters to embrace modern technology and move to more interactive learning systems, the time has come to examine just whether such a radical change is indeed warranted. The approaches taken by two undergraduate and postgraduate business faculties at a leading university are contrasted.
\end{abstract}

\section{INTRODUCTION}

Q ntil recent times the traditional face-to-face lecture has been the cornerstone of university teaching and learning. But a problem has recently emerged with many institutions reporting falling attendances (Morris, 2005) and a swing to consider other forms of imparting knowledge. To the forefront is the socalled technological revolution (Edlich, 1993) with a dazzling array of devices at the disposal of the modern lecturer. Common among these is the reliance on Microsoft PowerPoint overheads and of course the ready availability of the Internet. Those who refuse to yield completely to such revolutions are often accused of living in the stone age and retirement is sometimes suggested as an option.

There is no doubt that the Internet has caused for many a transformation in teaching from many points of view. For the lecturer it has opened up so-called "flexible" learning possibilities that now see entire degrees being offered without the student ever going near a classroom. As well as the convenience for the student, it also yields a darker side where there is now an abundance of reference material that can be downloaded at the press of a button. This of course also raises the hot topic issue of plagiarism, but that is a discussion for another day. Instead, this paper will explore the teaching culture at a leading graduate management school and an undergraduate school for business, examining the strategies each has adopted.

\section{TEACHING POSTGRADUATE MANAGEMENT STUDENTS}

Before delving into the merits of different approaches to teaching, it is interesting to note that Macquarie Graduate School of Management (MGSM) is ranked among the top fifty such schools in the world and arguably the finest in the country. They take very seriously the teaching capabilities of their staff for whom it is compulsory to have a student survey taken in every course they teach, usually about five times per faculty member each year. The audiences, mainly MBA students, have an average age of around thirty-five with substantial management experience. Indeed, in 2004 the Economist Intelligence Unit, Which MBA? in their 'Global Full-Time MBA Rankings' ranked them as No. 1 in the world for student quality.

Recently MGSM decided to introduce a 'reward' system for 'excellence in teaching' based on the comments and rating of the students. There were five lecturers of the forty or so who stood out way above the rest. What was revealing was that they all had one thing in common. None of them used PowerPoint to lecture, but rather the tried and tested method of writing on the whiteboard, talking to the audience and using an overhead projector whenever they felt any of these were necessary. Many educators base their presentations on their own experience as a student 
and it could be argued that this was simply the way they had learned and it was just being passed on by them. In this instance it was not the case since the ages of these five ranged from very early thirties to late fifties. What made them so outstanding?

It was clear that lectures could not simply be a one-way method of passively transferring information to the audience. The worst rated lecturers are generally those who forced the students to write down copious amounts of notes during their valuable lecture time. There was little or no discussion or interaction and it isn't surprising that students would be just as happy to have a printed copy of the lecture notes and stay home. And who could blame them? There is no intellectual challenge or stimulation and if a subject was a compulsory one where the students had little interest in the first place the result is one very unhappy customer.

One thing that the school has insisted on is the continuation of the face-to-face teaching method of presentation. It is true that a certain proportion of students may, as a consequence, not come to lectures but this does not diminish the importance of the contact between lecturer and student and student-student. It is even more so at MGSM where it is rightly felt that you simply cannot become a skilled manager earning an MBA simply by sitting in your lounge room, submitting material electronically, without the cut and thrust of academic life. And rightly so.

But that is not to say that staff are so rigid that they are resistant to any sort of change since to do so would be a marketing disaster with your competitors leaving you behind rather quickly. Syndicate groups, limiting class sizes, group work, presentations under the intense scrutiny of both lecturers and peers are all a part of making the time available a real learning experience. Demanding management students are not content with a 'simple' course that is easy to pass with little relevant content since, while passing is of course important, the main aim for them is to get value for the substantial amount of money they have paid to be a part of it. In general they are not patient or tolerant of a poor performance and have no difficulty in letting the Dean and anyone else in earshot know of their displeasure, even after the very first lecture, if they are unsatisfied. Teaching staff are well aware of this and there is no room for complacency at any time.

While there is no specific course at MGSM that can be currently undertaken via the web, it doesn't mean that there is no role for it in the teaching and learning experience. There is much material readily available to the students such as practice exercises, solutions, useful web sites and other important information. It's just not the case that lecture notes are put there as an alternative to coming to lectures. Attendance at lectures is always over 95 percent and the aim is for the students, who are largely part-time, to feel that their four hours of contact time each week have been quality time well spent and productive.

There is something in between giving the students all the lecture material and giving them nothing at all so that they have to copy everything down as it is said or transcribed on the board. One common technique is to give the students in printed form almost all of the lecture notes but with vital pieces missing. To fill these in they must be present at the lecture, solving problems either individually or in a group. Extra material from the lecturer, as it arises from class discussion, is written on the board or overhead projector as desired. But copious note taking is in this way avoided. Such techniques have served many lecturers here very well over the years. The idea of having a fistful of PowerPoint slides from which there is little or no deviation seems to be quite one-dimensional and consequently a big turn-off for many students since there seems to be a lack of associated spontaneity.

\section{TEACHING UNDERGRADUATE BUSINESS STUDENTS}

A particular challenge comes in an undergraduate offering at Macquarie University in Sydney, Australia, one of thirty-eight public universities in the country with an enrolment of about 25,000 students. There they cope with a massive course with the largest enrolment of any single subject at an Australian university. This course in introductory statistics caters for around some 2500 students each year and serves the statistical needs of all first year subject areas across the campus. One might be forgiven for thinking that the reason for such an achievement is that the material involved in statistics is so fascinating that students simply can't resist it. On the contrary, with very few exceptions, those enrolled are there simply because it is a compulsory prerequisite to a great many popular fields of study such as business, economics, accounting, computing and behavioural sciences, to name a few. 
The fact is that virtually no student comes to Macquarie to major in the area of statistics, and yet they have the largest statistics department in Australia and produce more than half of the country's statistics graduates. Excellence in teaching is the key and the statistics department has gone to extraordinary lengths to make the material relevant, exciting and challenging. With lecture theatres sometimes holding up to 500 students or more this is no easy task, particularly if many of the audience is somewhat hostile from the outset at having to be there in the first place. The lecturers are hand picked and the teaching material offered is first rate. It is virtually impossible to be all that 'interactive' with such a massive audience and staff find themselves lecturing on the stage that doubles as a movie theatre. There are two overhead projectors that are some twenty feet apart and an enormous cinemascope type screen behind. There is even a piano in the corner. Indeed you feel like a performer and that is exactly what you have to do. Holding the attention of the audience so that the two hours seemingly flashes by before they realise it has gone is quite challenging.

The sheer volume of the course has a sizeable impact on how the material is presented. Honed over the forty years that it has been in operation, introductory statistics has survived to lead the way in effective methods of very large group teaching. There are a number of components for student assessment including computer aided testing, mid-semester examinations and a final examination (that itself must be passed in order to complete the course). Without going into full details, twenty percent of the final mark comes from twelve weekly short answer questions (on the previous lecture's material) that the students answer by logging with their unique username and ID onto a website constructed specially for that purpose. The questions are randomly generated and no two students will get exactly the same test. In fact, they may have up to two attempts at each quiz and count the better of their two marks. Feedback on their performance is immediate and they are told of the correct way to do any problem in which they have been wrong. This is an automated system, tremendously resource intensive to set up, that now requires only minimal maintenance. At the end of the year the course administrators simple record a total score on all quizzes for each student.

A constant thorny question for the statistics staff at Macquarie was how to attract the students to do even more statistics subjects after their introductory course. What happened to the 2500 students after their first course? For the department to survive as a viable entity, it was essential to convince at least a portion of the captive audience from their first experience that the subject of statistics could be interesting, challenging and even relevant. Of course, this is no easy task. It was certainly true that some students continued in the subject because they had failed in their own major area (e.g. psychology, economics, accounting) and were simply looking for something else to fill in the time. But these were not nearly enough and it fell upon the staff to come up with an idea that would revolutionise the way the department organized their offerings.

\section{INNOVATIVE IDEAS}

From time immemorial, traditional statistics departments were steeped in theoretical courses with such thrilling names as Mathematical Statistics I, II and III, Stochastic Processes and Theory of Probability. Student numbers were dwindling along with a nationwide (even worldwide) decline in students studying mathematics and by association statistics suffered along with it. There was a crisis point fast approaching and many university statistics departments simply disappeared or became absorbed into mathematics departments (also in decline) to retain some kind of viability. At Macquarie there was a three pronged attack on the problem that changed the face of statistics and made it the best in the country.

Even before it began its revolution, there had been repeated calls for the department to remove itself from its location in the undergraduate business faculty to a different faculty where mathematics was taught. The department repeatedly fought against this proposal and won their battle, and in a gesture of seeming defiance dropping most of the mathematics prerequisites from their subjects. This naturally had an immediate negative effect on the number of students enrolled in mathematics courses but had the desired result of a modest rise in enrolments in other statistics courses. The downgrading of assumed mathematical knowledge had its predicted consequence without compromising the rigour of the material. But there was more to do. 
The next step in the process was firstly to rename existing subjects that had such unappealing titles it wasn't surprising that enrolments were critically low. Whether we like it or not, the word 'statistics' simply does not sound very exciting to the majority of students and so the term has been replaced where possible with another that might be more 'catchy', although the subject content was largely the same. Examples of these changes include replacing the course 'Applied Probability' with the name 'Risk and Chance' and 'Statistical Inference' with 'Modern Statistical Concepts'. The numbers in these subjects immediately increased markedly.

But these were for the most part still the same old subjects and it was now time to diversify and modernise the offerings in statistics where needed. Perhaps the most significant departure from the way in which the department offered its units was a radical change of direction in an attempt to lure some of the huge number of students enrolled in other business areas. To do this it was necessary to convince prospective customers that there were careers to be made in statistics and that employers were ready to embrace these skills. Although 'traditional' statistics had served reasonably well, the numbers of students had certainly levelled off and were in danger of falling off the radar altogether.

The situation was turned around by the introduction of a Bachelor of Commerce degree with a major in statistics that concentrated in the field of 'operations research'. This meant the introduction by the department of new offerings in statistics that covered new subjects, in addition to operations research itself. After much soul searching the following were introduced:

$\begin{array}{ll}\text { - } & \text { logistics } \\ \text { - } & \text { market research } \\ \text { - } & \text { Euality management } \\ \text { - } & \text { p-commerce } \\ & \text { project management }\end{array}$

The interest from students was immediate with the numbers enrolling at third year level operations research averaging over 200 per offering while some of the remaining theoretical statistics courses could only manage around 30 students. While some statistics staff lamented the 'downgrading' of these tried and trusted subjects, there is no doubt that the survival of the department was now largely dependent on the continued success of these operations research units that were firmly geared to the requirements of business and industry. This is a very important aspect as far as students are concerned since one of the most common questions asked is 'who will employ me if I get one of these degrees?'. There was now a much wider range of options in this respect and the department was sure it was on a winner. The path was now clear for the final assault on the program.

Having an attractive program in statistics at the higher levels was important enough, but it was even more essential that the students have their appetite whetted from a very early stage. The beginning introductory statistics unit covers the usual topics of descriptive techniques, hypothesis testing and linear regression. They became familiar with dedicated commercial statistical computer packages such as Minitab and demonstrated the virtues of the statistical attributes of Microsoft Excel since this was the program many of them would use after university life.

Although the compulsory first year course still had its predictable massive enrolments each year, around 90 percent of students were still choosing not to proceed further with the study of statistics - either because they weren't interested or they could not fit it into their program. In addition, there were simply many hundreds of students across the university who did not do any statistics units at all because they had no compulsion or inclination to do so. If they did enrol in a further subject, it had to be one with the unappealing title of 'Introduction to Statistical Practice'. In its early years the number of students enrolled in it had been relatively healthy but it too was suffering a decline due to a perception of its being somewhat boring in nature. If they didn't do this subject then they would not even get to the impressive new subjects offered at higher levels.

It was then that the final drastic change was made. With several other academics I conducted an informal survey of students to determine just what aspects of 'the real world' contained statistics that might be of interest to them. Perhaps of little surprise, the overwhelming favourite topic was gambling, followed closely by sport. No other 
application of statistics seemed to spark anywhere near as much interest at all, although there was some fascination in using statistics to study unusual phenomena such as the occult or the supernatural. The staff decided that a third topic that might appeal to students was the application to medicine, particularly to crime scene investigation. The stage was now set for the end of 'Introduction to Statistical Practice' and the dawn of a new subject 'Gambling, Sport and Medicine'.

\section{TEACHING STATISTICS USING GAMBLING, SPORT AND MEDICINE}

Catering to the market, it fell upon me to design and teach this brand new offering and to introduce it at the first year level with no pre-requisites alongside the course in introductory statistics. Since it would emanate from the same department, there could be no mistake that it was indeed a statistics subject. It took over a year in the planning of a syllabus and another six months to select the key staff that I would involve in teaching it. The media became aware of what was happening and I happily did several radio and television interviews promoting this radical approach to the subject. It was a defining moment, especially since gambling in particular involves sensitive issues with associated social problems and, moreover, a number of the students had not yet reached the legal gambling age of 18 years. As well as teaching from a statistical point of view, it was also necessary to talk about the negative side of gambling and the devastating impact it can have on those who do not gamble wisely and the effect on their families and friends.

Finally all was in readiness. All that remained was to see if students would be as taken with the new subject as we were! The response was overwhelming to say the least. In the first year over 400 students enrolled from across twenty-six different study areas across the campus. This was a huge increase on its predecessor and it was now up to me and my team to deliver the goods. Firstly it had to be made clear that this was not simply a subject that taught impressionable minds how to win at gambling - on the contrary, its aim was to present statistical principles in a way that captured the imagination but at the same time being challenging and informative.

It was correctly felt that one of the best ways of achieving this goal was to employ visual aids or 'props', and there was no shortage of these when it comes to the topics under discussion. The department was fortunate enough to receive a donation from Penrith Panthers Club, the largest club in Australia, of two working slot machines valued at around $\$ 30,000$. These machines turned out to be a highlight of the teaching of probability and expected returns and added a new dimension of excitement to the learning process. Other gambling devices that were purchased inexpensively included a two-up kip, coins, dice and packs of cards. A new roulette wheel was a more difficult issue since it costs around $\$ 25,000$ for a new one and $\$ 3500$ for one that was reconditioned. Since both were beyond the budget, an imitation plastic one costing several hundred dollars did the job nicely, although smaller in size than would have been liked in a large lecture theatre.

Gambling, the largest (and the most popular) component of the subject was then under control and sport was the next topic to have much the same treatment. To this end, teaching staff supplied their own equipment including cricket bats and balls, tennis racquets, basketballs, soccer balls and ice hockey sticks to illustrate how these games were played. It was then shown how strategies could be developed using basic statistical principles, the very same ones that had been previously used in demonstrating their use by means of tedious agricultural experiments and the like. Even if a student wasn't particularly interested in sport (about 40 percent of the audience was female) they were still fascinated by the whole episode.

The final section on medicine, also being the shortest, did not require many aids but did provide enormous scope for a wide ranging choice of topics. Among these is a regular lecture by one of the country's leading handwriting experts on just how statistics can be used to detect forged signatures on documents. Another deals with the interpretation of DNA and other evidence in trials and just how easy it is to bamboozle a jury (or a judge).

These were all techniques that could be readily used in the lecture theatre and classroom and when required the slot machines were wheeled to the classes on specially designed trolleys. But there was still something missing. There was no suitable textbook on these subjects and so one had to be written. This had taken me eighteen months but finally it was finished, naming it Gambling and Sport: a statistical approach (Croucher, 2003). Students readily purchased it owing to the contents containing a great deal of relevant material on the gambling and sport sections that 
covered over 75 precent of the subject. Other reference books on gambling included the classics by Epstein (1977) and Malmuth (1994) while for the medicine section there were plenty of printed notes given to the students. There was one final step to round off the complete package of innovation.

\section{WEB BASED TEACHING}

The educational experience needed just one more enhancement that would require a great deal of time and, naturally, some money. Fortunately, Macquarie believed in the merits of the course to the extent that it awarded me the largest ever teaching grant (still true to this day) to present the subject as one that effectively utilised the capabilities of the World Wide Web. This was a two year project that initially involved considerable time developing the specifications for a web site unlike any that had been devised before at the university. It was pioneer work that presented a real challenge to the programmers whose task it was to put my expectations into practice. There were others who had written well-known references in the design goals in a learning environment and variations in the delivery of instruction such as Duffy and Cunningham (1996), Lefoe (1998) and Wilson (1996). This project was going to use these principles to their fullest.

Space does not permit a full description of the harrowing time spent bringing the venture to its conclusion, but suffice to illustrate some of the features that it has to offer. The opening screen of the subject (also known as STAT175) website (with URL http://online.mq.edu.au/pub/STAT175/) is shown in Figure 1. When the user clicks on any of the three icons GAMBLING, SPORT or MEDICINE they are then led through a series of public pages that describe various aspects of the unit including detailed information on each topic along with the unit outline and due dates of assessment.

To access more in-depth material relevant to the unit, users click on the LOGIN icon and must supply a password. Each student is given their own unique password for the duration of the subject. This enables the teaching staff to communicate directly with each individual and they can also contact each other privately. The actual lecture notes are not be placed on the web since it is felt that this would be a discouragement to attending lectures. The specifications of the web site include the following requirements that have their individual icon on the screen.

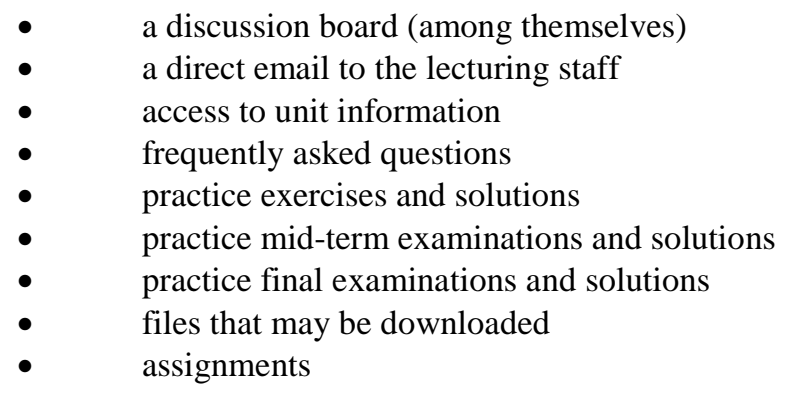

After logging on to the private section of the site, the screen presented is that shown in Figure 2. Undoubtedly the most exciting feature of these icons is the introduction of an animated simulation component in which students can play games such as Two-up, Keno, Roulette, Craps, Keno Heads or Tails? and even slot (poker) machines. The simulations, written using the powerful authoring environment of Macromedia's Director Lingo, were the most expensive and complex part of the site but undoubtedly well worth the effort since, apart from being colourful and challenging, they can be used to test strategies and the verify the theoretical statistical results. The simulations screen is shown in Figure 3. 
Figure 1: The opening screen of the public section of the website for Gambling, Sport and Medicine

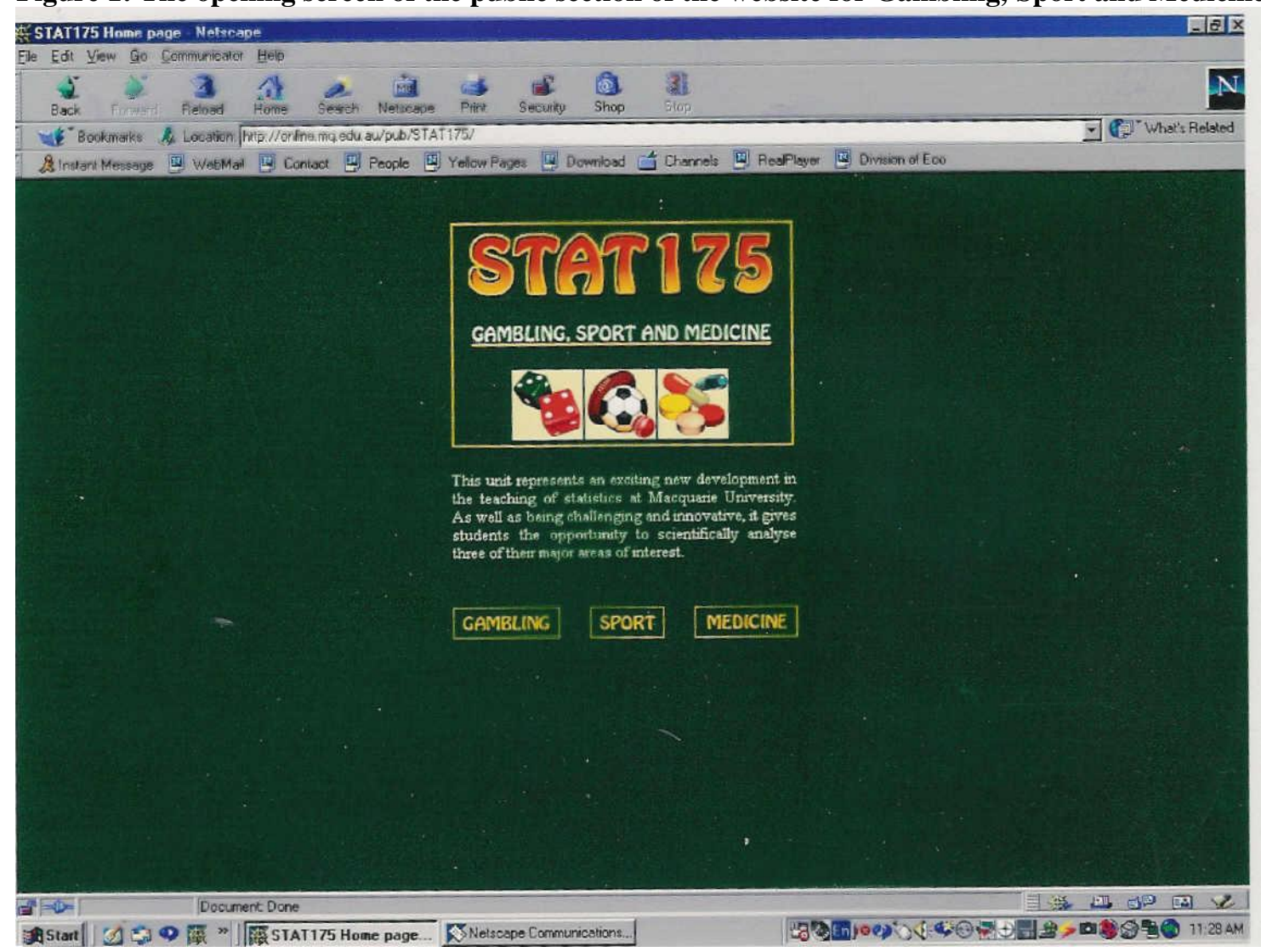

The Olympic Games in 2000 and 2004 provided a golden opportunity to demonstrate statistical techniques using sporting data. In particular, one lively topic of discussion was the times and distances that athletes and swimmers would have to achieve in order to win a gold medal. With an abundance of historical data, students were able to use their statistical skills to come up with various intervals within which they feel the winning performance would lie. Then they could compare their answers with what actually happened.

Apart from the Olympics, there are a number of popular sports including football, cricket and basketball that are all covered in some aspect. Some of these are along the lines of developing or testing of strategies for play, while for others it is considering the effect of rule changes. One of the beauties of teaching statistical principles using sport is that there is never any shortage of information to analyse and it is always topical. In all, after six weeks of learning about the statistics of gambling, the next four weeks is spent on the statistics of sport. Useful references here included books by Ladany \& Machol (1977), Bennett (1998) and Butenko et al (2004).

Although the sports and medical statistics components of the course are well liked by the students, they do not enjoy the popularity of the gambling section. However, for those students who are keen to undertake further studies in the fascinating area of medical statistics, the department offers a complete unit at the higher level in epidemiology and a number of graduates with this interest have gone on to find employment in this area. 
Figure 2: The opening screen of the private section of the website for 'Gambling, Sport and Medicine
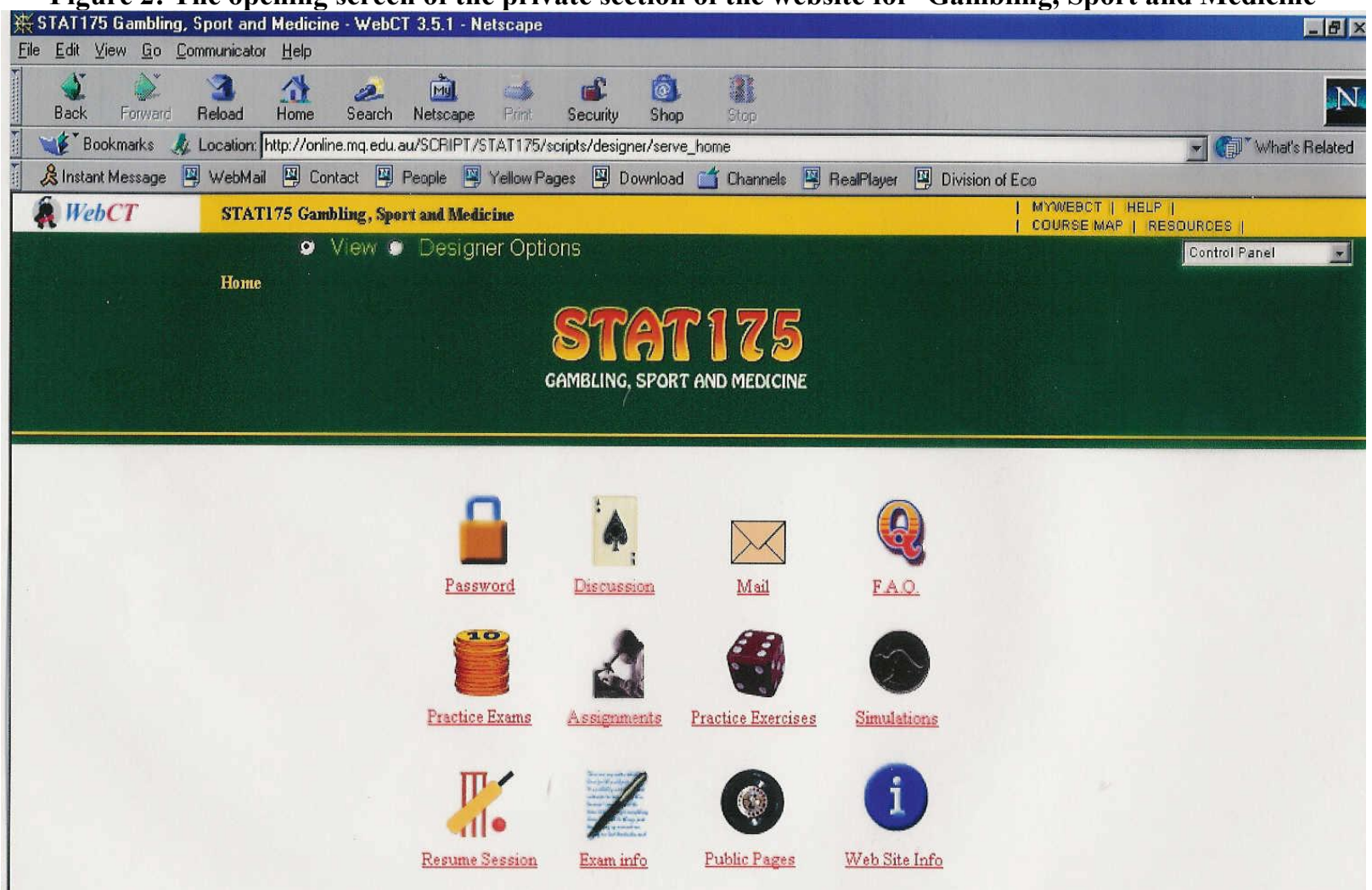

Undoubtedly the subject, which makes no secret of the fact that it features gambling, has been an outstanding success and has in a short space of time attracted thousands of students along with hundreds of thousands of dollars in funds to the department. The media has continued to very supportive, as has the gaming industry itself in assisting a venture that provides an essential public education program in this controversial area. The university has even featured it on a promotional video and DVD and at least two other universities have tried to imitate the success by offering their own versions.

\section{REMARKS}

To answer the question posed by the title of this paper, the answer is a firm 'yes'. There are many ways in which a teacher can be effective and what techniques work for some will be a disaster for others. Curiously, Outstanding Teacher Awards at Macquarie University are much coveted and awarded by a panel who has never actually seen the recipient at work in the classroom. To be successful, superior student ratings over a sustained period of years are essential but not sufficient. It is also necessary for them to write a ten page treatise on, among other things, their philosophy of teaching. The next step is to be selected, if the university deems it, as an entrant in the national Australian Awards for University Teaching scheme held each year.

It comes as no surprise that some classroom lecturers are pure magic with just a marker pen and a whiteboard at their disposal while others flounder no matter what modern teaching aid is at their disposal. That is why, with an increasing emphasis on good teaching, both the undergraduate and postgraduate business faculties at Macquarie have appointed their own Associate Dean/Director of Teaching and Learning to bring out the best in their staff. In doing so they have high expectations on a general raising of the level of teaching ability of their staff. 
Figure 3 The gambling simulations for the website of 'Gambling, Sport and Medicine

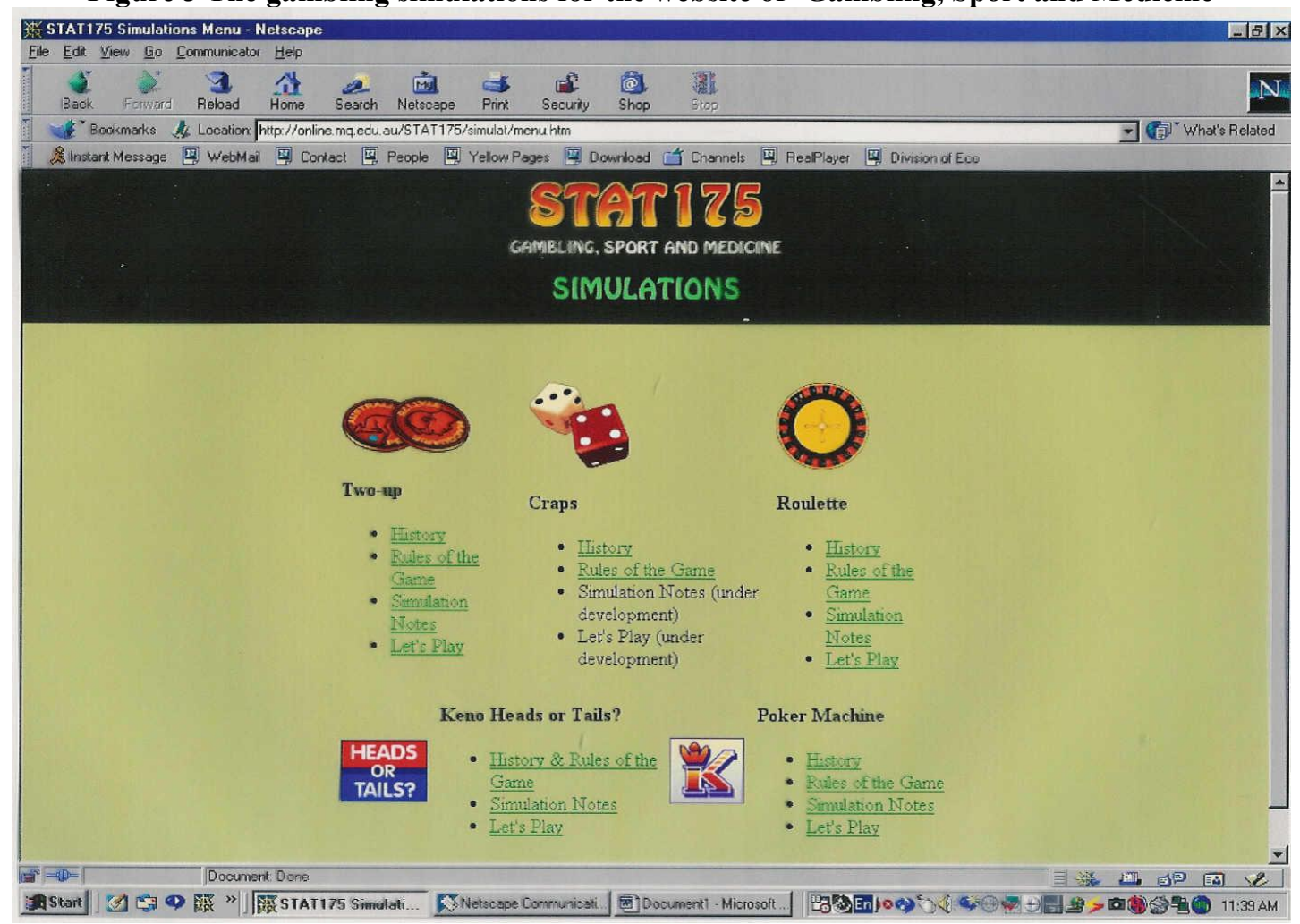

As far as the new subject in gambling, sport and medicine goes, the outcomes for those involved in this fascinating project have been extremely rewarding. The pressure is always on academics to be able to present their material in a way that is relevant, challenging and stimulating. Although this may be easier to do in some areas of study than others, the results are well rewarded, as evidenced by the Macquarie experience in this unit. The hunt is now on to repeat this success by offering other types of courses that will also attract the attention of students who otherwise would not have ever envisaged studying a particular subject area.

\section{REFERENCES}

1. $\quad$ Bennett, J. (ed.), (1998). Statistics in Sport. Arnold, England.

2. Butenko, S., Gil-Lafuente, J. and Pardalos, P. M. (eds.). (2004). Economics, Management and Optimization in Sports, Springer-Verlag, Berlin.

3. Croucher, J. (2003). Gambling and Sport: a statistical approach. Macquarie Lighthouse Press, Sydney.

4. Duffy, T.M. and Cunningham, D.J. (1996). Constructivism: Implications for the design and delivery of instruction. In D.H. Jonassen (ed.) Handbook of Research for Educational Communications and Technology, NY: Macmillan Library Reference, USA.

5. $\quad$ Edlich, R.F. (1993) My last lecture. Journal of Emerging Medicine, 11(6): 771-774

6. $\quad$ Epstein, R. (1977). The Theory of Gambling and Statistical Logic. Academic Press, USA.

7. Ladany, S.P. and Machol, R.E. (eds) (1977). Optimal Strategies in Sports. North Holland, New York.

8. Lefoe, G. (1998). Creating constructionist learning environments on the Web: the challenge in higher education. Ascilite 98 Conference proceedings, URL http://www.ascilite.org.au/conferences/wollongong98/ asc98-pdf/lefoe00162.pdf

9. Malmuth M. (1994). Gambling Theory and Other Topics. $4^{\text {th }}$ edition, Two Plus Two Pub., USA. 
10. Wilson, B.G. (ed.) (1996). Constructionist learning environment: case studies in instructional design. Educational Technology Publication, Englewood Cliffs, N.J., USA

11. Morris, R. (2005) Quoted in Empty lecture halls in online campus by Andrew Stevenson, Sydney Morning Herald, Feb. 26-27, p.4

\section{NOTES}

